\title{
The impact of the warm phase of ENSO (EI Niño Southern Oscillation) events on water resource availability of tropical catchments in Central Sulawesi, Indonesia
}

\author{
C. Leemhuis and G. Gerold \\ Department of Geography, University of Göttingen, Germany
}

Received: 13 May 2005 - Revised: 2 December 2005 - Accepted: 5 December 2005 - Published: 16 February 2006

\begin{abstract}
Precipitation anomalies caused by the warm phase (El Niño) of the ENSO cycle lead to a strong decrease of water resources in South-East Asia. The aim of this work is to study the impact of warm phase ENSO caused precipitation anomalies on the water balance of a mesoscale tropical catchment in Central Sulawesi, Indonesia using a scenario analysis. We applied statistically generated precipitation anomalies caused by warm phase ENSO events on a validated hydrological model of the Palu River catchment $\left(2694 \mathrm{~km}^{2}\right)$ to investigate the implications of the generated ENSO scenarios on the total annual water balance, the annual discharge regime and the discharge variability. Moreover we analysed the influence of various catchment characteristics during warm phase ENSO conditions on the discharge variability through a comparison of different sub-catchment types. The results of the scenario analysis proved a severe decline of the annual discharge rate during warm phase ENSO conditions and an increase of the overall discharge variability.
\end{abstract}

\section{Introduction}

The most recent two extreme warm events of the ENSO cycle 1982/83 and 1997/98 severely hit the socio-economy of main parts of Indonesia (Voituriez and Jacques, 2000). As the climate variability is not homogeneous over the whole archipelago of Indonesia, warm ENSO events cause negative precipitation anomalies of diverse magnitude and duration in different regions (Aldrian, 2003). Therefore possible mitigation strategies have to be developed on a regional scale and integrated into long term Integrated Water Resource Management (IWRM) strategies, which operate on a catchment scale (Global Water Partnership, 2000). The general objective of this study is to investigate and quantify the impact of ENSO

Correspondence to: C. Leemhuis

(cleemhu@gwdg.de) caused climate variability on the water budget and the implications for water resources of a mesoscale tropical catchment in Central Sulawesi, Indonesia.

\section{Research area}

The mesoscale Palu River catchment $\left(1^{\circ} 20^{\prime} \mathrm{S}, 21^{\circ} 01^{\prime} \mathrm{E}\right)$ is located in Central Sulawesi, Indonesia (Fig. 1) and covers an area of $2694 \mathrm{~km}^{2}$. The topography of the catchment varies from 0-2500 $\mathrm{m}$ a.s.l. Due to the monsoonal setting of Central Sulawesi, warm phase ENSO events are described by decreased precipitation from June till October, which corresponds with the dry period of the region.

\section{Methodology and data}

In order to quantify the impact of ENSO caused precipitation anomalies on the water balance of the catchment we applied a model based ENSO scenario analysis. The physically based distributed Water balance and Flow simulation model WASIM-ETH (Schulla and Jasper, 1998) has been successfully applied to the Gumbasa subcatchment $\left(1275 \mathrm{~km}^{2}\right)$. The chosen grid scale was $500 \mathrm{~m} \times 500 \mathrm{~m}$ and the temporal resolution was a daily time step. We conducted the calibration of the hydrological model with the parameter estimation model PEST (Doherty, 1999). The calculated model efficiency of the calibration and validation period achieved satisfactory results, which proved the chosen hydrological model as a suitable prediction tool.

The simulation of the water balance was carried out from 2002-2004. To obtain a feasible data source for the hydrological model we launched an intense monitoring program of hydrological and meteorological data in September 2002, which is operating till present. Furthermore we selected the Gumbasa River catchment and two of its sub-catchments as 

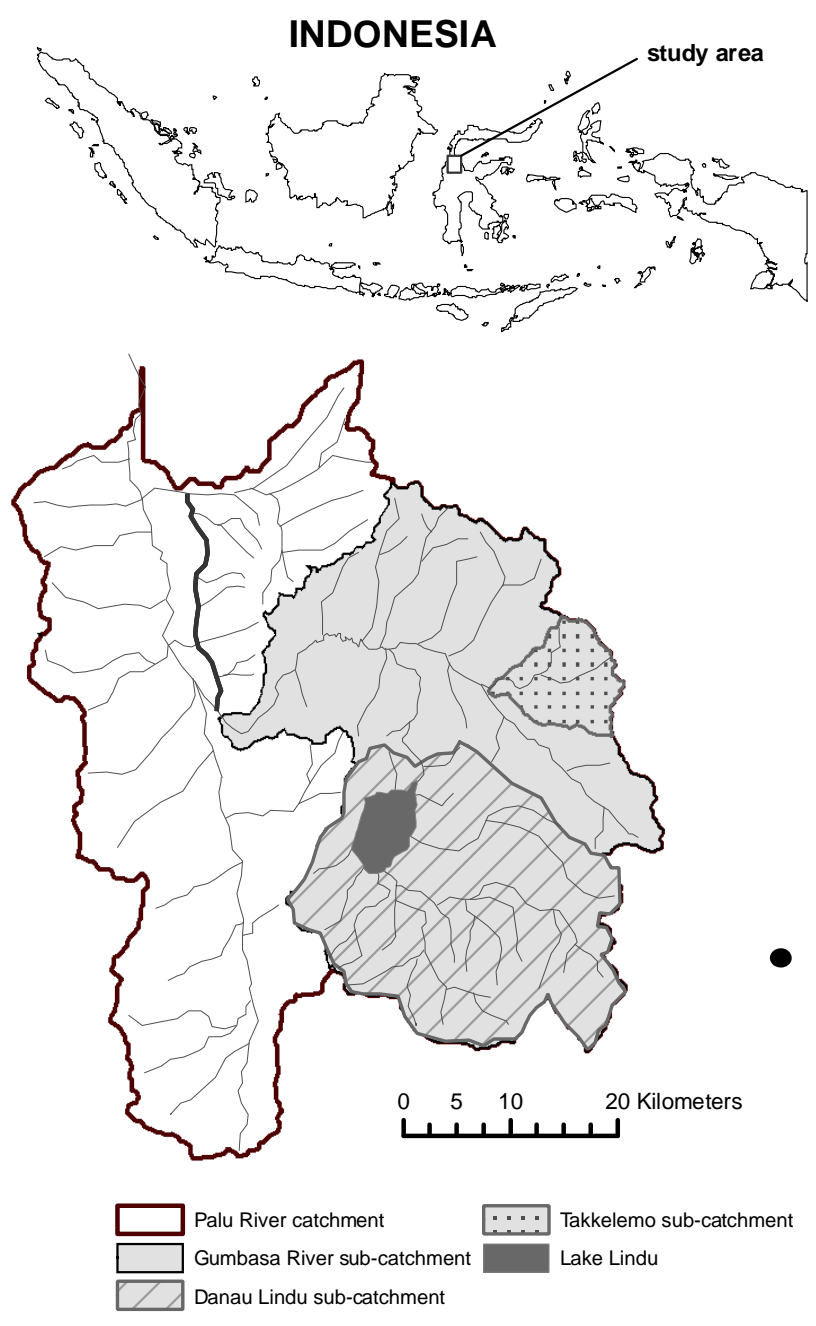

Fig. 1. The Palu River catchment and its sub-catchments, Central Sulawesi, Indonesia.

sample catchments to evaluate the overall influence of catchment characteristics on the water balance during normal and warm phase ENSO conditions.

\section{ENSO scenario}

The modelling year 2003 serves as a reference year for "normal" non- warm phase ENSO conditions and moreover as basis data for the generation of ENSO caused precipitation anomalies. In order to generate a spatial and temporal variable warm phase ENSO scenario as input data for a hydrological model of the Gumbasa River catchment we applied a statistical scenario approach.

The statistical scenario approach comprises two graded warm phase ENSO scenarios which reflect the mean anomaly of all observed ENSO caused precipitation anomalies (1987, 1991, 1994, and 1997) and the extreme warm phase ENSO event of 1997. For the input of the hydrological model we applied the monthly observed precipitation anomalies to the
Table 1. Monthly ENSO caused precipitation anomalies for an average and a strong warm phase ENSO scenario (97), Pandaya climate station.

\begin{tabular}{lcc}
\hline $\begin{array}{l}\text { Pandaya }(1050 \mathrm{~m} \text { a.s.1.) } \\
\left(1^{\circ} 04^{\prime} 07 \mathrm{~S}, 120^{\circ} 04^{\prime} 44 \mathrm{E}\right)\end{array}$ & average & 97 \\
\hline June & $-25 \%$ & $-56 \%$ \\
July & $-35 \%$ & $-13 \%$ \\
August & $-74 \%$ & $-94 \%$ \\
September & $-90 \%$ & $-100 \%$ \\
October & $-71 \%$ & $-50 \%$ \\
\hline
\end{tabular}

Table 2. Monthly ENSO caused precipitation anomalies for an average and a strong warm phase ENSO scenario (97), Bora climate station.

\begin{tabular}{lcc}
\hline $\begin{array}{l}\text { Bora }(125 \mathrm{~m} \text { a.s.1.) } \\
\left(1^{\circ} 01^{\prime} 39 \mathrm{~S}, 119^{\circ} 55^{\prime} 53 \mathrm{E}\right)\end{array}$ & average & 97 \\
\hline June & $-5 \%$ & $-13 \%$ \\
July & $-53 \%$ & $-81 \%$ \\
August & $-20 \%$ & $-100 \%$ \\
September & $-83 \%$ & $-100 \%$ \\
October & $-20 \%$ & $-40 \%$ \\
\hline
\end{tabular}

corresponding monthly precipitation rate of the basis year during the ENSO affected months from June till October. Tables 1 and 2 describes the applied precipitation anomalies for two selected climate station within the research area.

\section{Results}

We performed warm phase ENSO scenario simulations with WASIM-ETH for the described precipitation anomaly scenarios. The results of the scenario simulations were analysed according to the spatial variability of the different subcatchments, the changes in the water balance and the temporal variability. Besides the Gumbasa River catchment we selected two subcatchments for a detailed analysis of the influence of catchment characteristics on the water balance during drought periods. The selected subcatchment comprises the medium mesoscale Danau Lindu subcatchment $\left(525 \mathrm{~km}^{2}\right)$ with a high storage capability and the fast responding small mesoscale Takkelemo headwater catchment $\left(79 \mathrm{~km}^{2}\right)$.

The discharge is one of the most important water balance components according to its significance for the water resource availability. Figure 2 describes the low pass flow duration curve of the Danau Lindu (A), the Takkelemo (B) and the Gumbasa River (C) catchment for the basis year 2003 and the applied average warm phase ENSO scenario (EAL0) and the strong warm phase ENSO event 1997 (EBL0). The low pass flow duration curve displays the annual number of days which fall below a certain discharge and describes the overall yearly discharge variability of the catchment. The low pass 

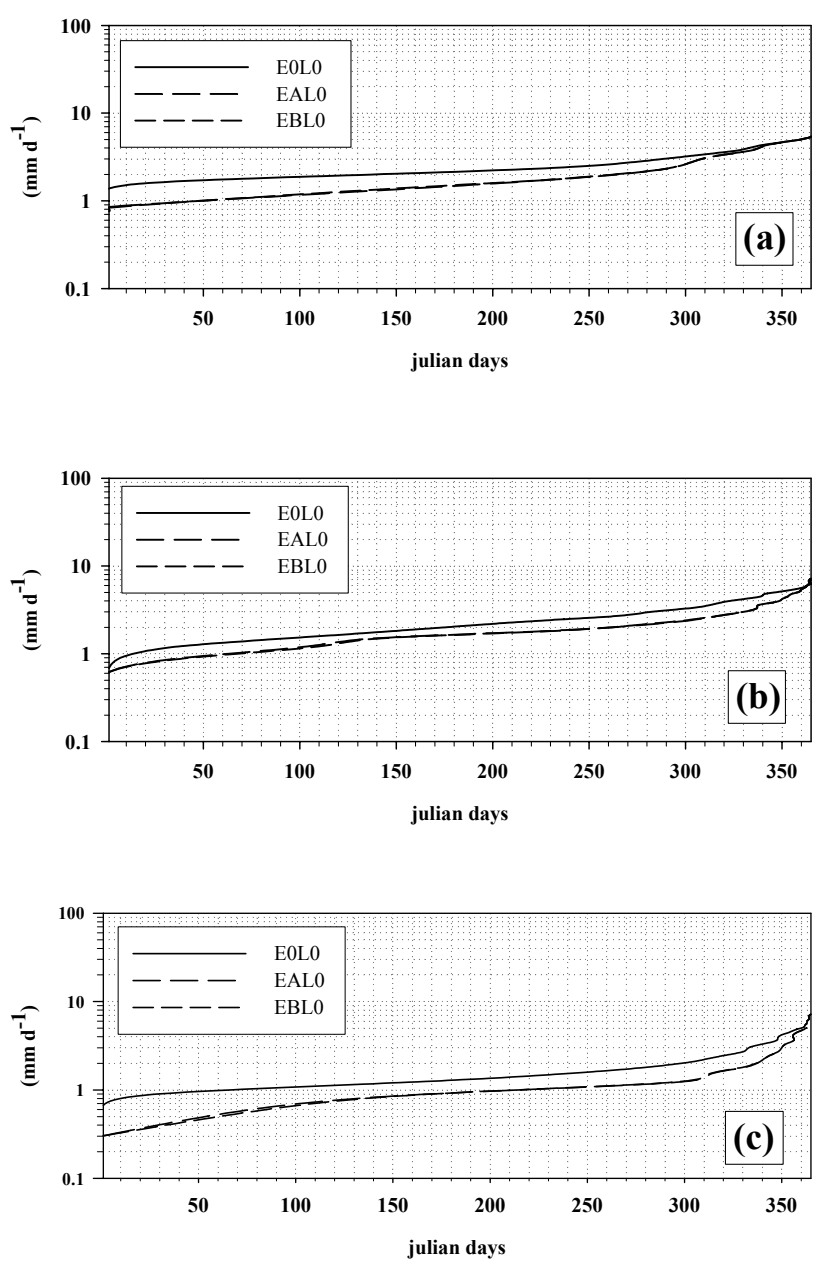

Fig. 2. Low pass flow duration curve for the control run 2003 (EOL0) and warm phase ENSO scenario EAL0 and EBLO for the Danau Lindu (a), Takkelemo (b) and Gumbasa River (c) catchment.

flow duration curves for all catchment types indicate an overall increase of the discharge variability due to a decrease of the low water discharge.

The decrease of the low water discharge is most significant for the Gumbasa River catchment, whereas the small fast responding Takkelemo catchment only shows a slight decrease. Due to the high retention capacity of Lake Lindu the Danau Lindu catchment has the lowest discharge variability during normal conditions. However, the yearly low water and mean discharge is also highly affected during warm phase ENSO events. The low pass flow duration curve analysis demonstrates that for all catchment types low water and mean discharge are highly affected during warm ENSO events. Furthermore, the applied degraded warm ENSO scenarios EAL0 and EBL0 have an almost similar impact on the yearly discharge variability. The relative similar impact of the applied warm phase ENSO events can be explained by the strong influence of the Pandaya climate station on the areal precipitation generation of the Gumbasa River catchment. For the Pandaya station, the monthly precipitation anomaly is vari-
Table 3. Comparison of the yearly water balance for the Gumbasa River catchment for normal conditions 2003 (E0L0), and warm phase ENSO scenarios EAL0 and EBLO.

\begin{tabular}{lcccc}
\hline Gumbasa catchment & & EOL0 & EAL0 & EBL0 \\
\hline Precipitation (P) & {$[\mathrm{mm}]$} & 2150 & 1614 & 1586 \\
$\Delta \mathrm{P}$ & {$[\%]$} & - & -24.9 & -26.2 \\
Evapotranspiration (ETR) & {$[\mathrm{mm}]$} & 1543 & 1496 & 1487 \\
$\Delta$ ETR & {$[\%]$} & - & -3.0 & -3.1 \\
Total discharge (Q) & {$[\mathrm{mm}]$} & 590 & 401 & 397 \\
$\Delta \mathrm{Q}$ & {$[\%]$} & - & -32.0 & -32.7 \\
\hline
\end{tabular}

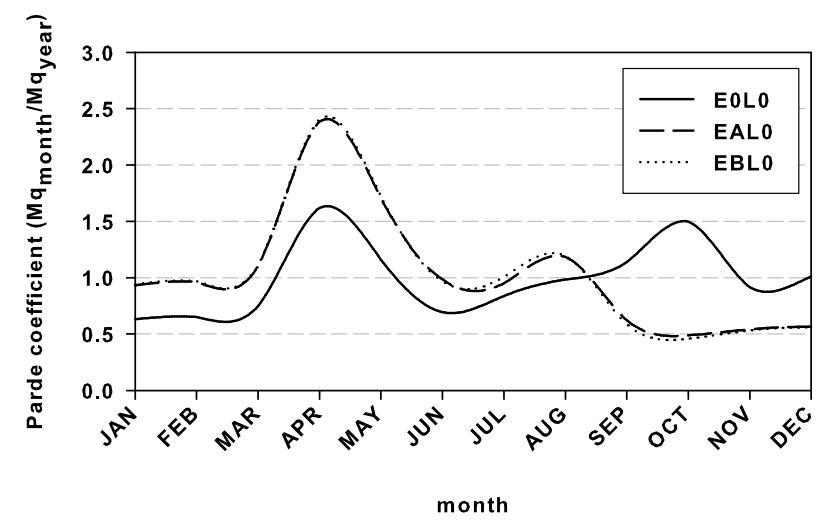

Fig. 3. Monthly regime for actual conditions 2003 (EOL0) and warm phase ENSO scenarios EAL0 and EBL0, Gumbasa River catchment.

able for both scenarios. However, if the yearly mean precipitation anomaly is calculated for both scenarios, they hardly differ with a mean value of $-59 \%$ for scenario EAL0 and $-63 \%$ for scenario EBL0.

The temporal discharge variability of the Gumbasa River catchment is reflected by the diagram of the monthly discharge regime for the normal year and the applied warm ENSO scenarios EAL0 and EBL0 (Fig. 3). The comparison of the yearly discharge regime variability expresses the overall increased discharge variability during warm phase ENSO events. Since the negative regime trend starts in early August, this period marks the point when ENSO caused precipitation anomalies negatively affect the discharge regime trend of the catchment. Although the applied warm phase ENSO scenarios have an impact on the areal precipitation till end of October the impact for the discharge regime lasts till end of December. The comparison of the annual water balance for normal and warm phase ENSO conditions quantifies the changes in the water balance. Table 3 compares the climate scenarios induced changes of the yearly water balance components precipitation $(\mathrm{P})$, evapotranspiration (ETR) and total discharge $(\mathrm{Q})$ for the Gumbasa River catchment. The current conditions of 2003 serve as a control run for the evaluation of the proportional changes. The simulated decrease 
of the yearly total discharge by $32 \%$ for warm phase ENSO scenario EAL0 and $32.7 \%$ for EBL0 demonstrate that ENSO caused precipitation anomalies have a significant impact on the water resources of the Gumbasa River watershed. The annual water balance for both warm phase ENSO scenario simulations record similar trends, which responds to the analysis of the monthly regime and the low pass flow duration curve.

\section{Conclusions}

In the case study presented here the impact of ENSO caused precipitation anomalies on the water resources of a mesoscale tropical catchment was analysed using a scenario analysis based on a hydrological modelling approach. In comparison with the within ENSO hydrological research commonly conducted cross-correlations of discharge time series and ENSO indices like SST or SOI (Guitierrez and Dracup, 2001; Amakesekera et al., 1996; Collischom et al., 2001; Eltahir, 1996; Simpson et al., 1993) an ENSO scenario analysis by simulation runs of a validated hydrological model provides a more detailed analysis of the possible hydrological system responses of the catchment. We demonstrated that during warm phase ENSO events the yearly discharge variability increases for a tropical mesoscale catchment in Central Sulawesi, Indonesia. However, the magnitude of discharge variability increase is highly related to the catchment characteristics. The warm phase ENSO simulation run of the hydrological model quantified the annual discharge reduction to less than $30 \%$ of the basis year discharge, indicating serious short cuts of water resource availability for the irrigated rice cultivation of the catchment.

Edited by: P. Fabian and J. L. Santos

Reviewed by: M. McPhaden and M. Richter

\section{References}

Aldrian, E.: Simulations of Indonesian Rainfall with a Hierachy of Climate Models, Dissertation, Universität Hamburg, 23-45, 2003.

Amarasekera, K. N., Lee, R. F., Williams, E. R., and Eltahir, E.: ENSO and the natural variability in the flow of tropical rivers, J. Hydrol., 200, 24-39, 1996.

Collischonn, W., Tucci, C. E. M., and Clarke, R. T.: Further evidence of changes in the hydrological regime of the River Paraguay: part of a wider phenomenon of climate change?, J. Hydrol., 245, 218-238, 2001.

Doherty, J.: Model-Independent Parameter Estimation, User manual, 5th edition, Watermark Numerical Computing, 279 pp, 1999.

Eltahir, E.: El Niño and the natural variability in the flow of the Nile River, Water Resour. Res., 32, 131-137, 1996.

Global Water Partnership: Integrated Water resource management, TAC Background Papers, No. 4, Stockholm, 51-67, 2000.

Gutierrez, F. and Dracup, J.: An analysis of the feasibility of longrange streamflow forecasting for Colombia using El Niño Southern Oscillation indicators, J. Hydrol., 246, 181-196, 2001.

Schulla, J. and Jasper, K.: Model description WASIM-ETH, Institute for Climate Research, ETH, Zürich1, 166 pp, 2000.

Simpson, H. J., Cane, M. A., Herzog, A. L., and Zebiak, S. E.: Annual River Discharge in Southeastern Australia Related to El Niño Southern-Oscillation Forecasts of Sea Surface Temperartures, Water Resour. Res., 29, 3671-3680, 1993.

Voituriez, B. and Jacques, G.: El Niño - Fact and fiction, UNESCO, Paris, 65-96, 2000. 